\title{
CARACTERIZAÇÃO DE CULTIVARES DE SOJA POR DESCRITORES MORFOLÓGICOS E MARCADORES BIOQUÍMICOS DE PROTEÍNAS E ISOENZIMAS ${ }^{1}$
}

\author{
ELISA SERRA NEGRA VIEIRA² ${ }^{2}$ ÉDILA VILELA DE RESENDE VON PINHO ${ }^{3}$ \\ MARIA DAS GRAÇAS GUIMARÃES CARVALHO ${ }^{4}$ PRISCILA ALVES DA SILVA 5 .
}

\begin{abstract}
RESUMO - A utilização de descritores morfológicos e marcadores bioquímicos de proteínas e enzimas têm sido recomendados para fins de caracterização de cultivares de soja. O objetivo do presente trabalho foi empregar tais descritores e marcadores na identificação de dez cultivares de soja. Os marcadores morfológicos avaliados nos estádios de plântula, planta e semente foram os recomendados pela Lei de Proteção de Cultivares e UPOV, mostrando-se eficientes na separação das dez cultivares. Marcadores específicos para sete das dez cultivares foram obtidos. A utilização de proteínas de armazenamento possibilitou a separação das cultivares em três grupos: 1) Conquista, BR/IAC 21 e Garantia; 2) Liderança, Confiança e Monarca; 3) Splendor, UFV 16, FT 2000 e Vencedora. Os sistemas enzimáticos superóxido dismutase, diaforase, fosfoglucomutase, esterase, álcool desidrogenase, isocitrado desidrogenase e peroxidase separaram as cultivares em seis grupos: 1) Conquista e Confiança; 2) Splendor e FT 2000; 3) UFV 16 e Garantia; 4) BRIAC 21; 5) Liderança e Monarca; 6) Vencedora. O emprego de marcadores bioquímicos de proteínas e caracterização de cultivares de soja.
\end{abstract}

Termos para indexação: Glycine max, proteção de cultivares, semente.

\section{SOYBEAN CULTIVAR CHARACTERIZATION USING MORPHOLOGICAL DESCRIPTORS AND PROTEIN AND ISOENZYME BIOCHEMICAL MARKERS}

\begin{abstract}
The use of morphological descriptors and protein and isozymes biochemical markers have been recommended for soybean cultivar characterization. The aim of this study was to identify ten soybean cultivars using such descriptors and markers. The morphological descriptors evaluated in seedlings, plants and seeds were those recommended by the Cultivars Protection Act and UPOV and were efficient in cultivar separation. Specific markers for seven of the ten cultivars were obtained. Total protein separated the cultivars into three groups: 1) Conquista, BRIAC 21 and Garantia; 2) Liderança, Confiança and Monarca; 3) Splendor, UFV 16, FT 2000 and Vencedora. Superoxide dismutase, diaforase, phosphoglucomutase, esterase, alcohol desidrogenase, isocitrado desidrogenase and peroxidase separated the cultivars into six groups: 1) Conquista and Confiança;
\end{abstract}

\footnotetext{
${ }^{1}$ Submetido em 02/09/2008. Aceito para publicação em 19/01/2009. Parte da Tese de Doutorado do primeiro autor apresentada a UFLA.

${ }^{2}$ Eng. Agra., Dra., pesquisadora do Núcleo de Biotecnologia, Cooperativa Central de Pesquisa Agrícola, Caixa Postal 301, CEP 85813-450, Cascavel, esnegra@coodetec.com.br
}

${ }^{3}$ Eng. Agr., Dr., Prof. do Departamento de Sementes, UFLA, Caixa Postal

3037 CEP: 37200-00, Lavras, edila@ufla.br

${ }^{4}$ Eng. Agr., Dr., Professora do Departamento de Sementes, UFLA, Caixa Postal 3037 CEP: 37200-00, Lavras, mariagcv@ufla.br

${ }^{5}$ Eng. Agr., doutoranda do Departamento de Sementes, UFLA, Caixa Postal 3037 CEP: 37200-000, Lavras, priscilaufla@yahoo.com.br 


\begin{abstract}
2) Splendor and FT 2000; 3) UFV 16 and Garantia; 4) BRIAC 21; 5) Liderança and Monarca; 6) Vendedora. The use of biochemical markers with morphological descriptors was useful to soybean cultivar characterization.
\end{abstract}

Index terms: Glycine max, cultivar protection, seed.

\section{INTRODUÇÃO}

O Brasil é o segundo produtor mundial de soja, a qual é uma das mais importantes culturas para o agronegócio brasileiro (Agrianual, 2008).

Com a promulgação da Lei de Proteção de Cultivares (LPC) (Brasil, 1997), o número de novas cultivares de soja, como também de outras culturas, vem aumentando a cada safra. A soja é a cultura que apresenta o maior número de pedidos de proteção e o maior número de cultivares protegidas no Brasil (SNPC, 2008). De acordo com a Nova Lei de Sementes e Mudas (Brasil, 2003), uma cultivar para ser protegida, deve ser registrada e submetida ao teste de distinguibilidade, homogeneidade e estabilidade, também denominado teste DHE. Este teste consiste na avaliação de uma série de características morfológicas nos diferentes estádios de desenvolvimento da planta. Tais características, denominadas descritores mínimos, são específicas para cada espécie e recomendadas pelo Serviço Nacional de Proteção de Cultivares (SNPC).

Os descritores mínimos recomendados para soja constituem-se de características morfológicas a serem avaliadas nas sementes, plântulas e plantas adultas e, para fins especiais, avaliações adicionais como eletroforese de proteínas e enzimas (Brasil, 1997).

Os descritores morfológicos são tradicionalmente utilizados na caracterização de cultivares de soja como também de outras culturas. Apesar de recomendado, o emprego destes descritores apresenta algumas limitações como sofrerem e efeito do ambiente, não sendo estáveis, e muitos serem avaliados na fase adulta das plantas, o que requer tempo e espaço físico para as avaliações (Vieira, 2000). Além disso, o número de descritores recomendados para soja, os quais somam um total de trinta e oito, tem sido insuficiente e novos descritores estão sendo avaliados (Nogueira et al., 2007; Boldt et al., 2007).

Marcadores bioquímicos de proteínas e enzimas para a identificação de cultivares de soja são recomendados pela UPOV, mas não ainda pela ISTA, provavelmente devido à falta de protocolos padronizados e testados (ISTA, 2007;
UPOV, 1998). A utilização de marcadores bioquímicos oferece vantagens como a obtenção de resultados num prazo de 24-48 horas e a simplicidade de operação.

Padrões eletroforéticos de proteínas de armazenamento também são utilizados para fins de caracterização de cultivares. Proteínas de armazenamento foram utilizadas na caracterização de cultivares de soja e mostraram-se bastante estáveis, enquanto que padrões eletroforéticos de proteínas resistentes ao calor mostraram-se promissores para a caracterização de cultivares de algodão e milho (Mann, 2002; Roveri José et al., 2004). No entanto, em relação às últimas, existem na literatura, poucas informações sobre o polimorfismo destas proteínas para fins de caracterização de cultivares de soja (Menezes et al., 2008).

Marcadores enzimáticos também têm sido utilizados na caracterização de cultivares de várias espécies como arroz (Bonow et al., 2001), feijão (Vieira, 2000), milho (Salgado, 2001) e soja (Aguero, 2002). Os marcadores isoenzimáticos são de caráter co-dominante, possibilitando a separação de genótipos homozigotos e heterozigotos, o que é de grande utilidade nos testes de certificação da pureza genética (Ferreira e Grattapaglia, 1998). Além disso, o controle genético da maioria das enzimas já é conhecido, o que facilita a interpretação dos zimogramas (Alfenas, 1998). Sistemas enzimáticos como esterase, álcool desidrogenase, urease, malato desidrogenase, fosfatase alcalina, leucina aminopeptidase, superóxido dismutase, fosfoglucoisomerase, 6-fosfogluconato desidrogenase, entre outros, se mostraram polimórficos na separação de cultivares de soja (Aguero, 2002; Anti, 2000).

Sendo assim, objetivou-se, no presente trabalho, caracterizar dez cultivares de soja por meio de descritores morfológicos e marcadores bioquímicos de proteínas e enzimas, bem como avaliar a eficiência de protocolos de extração de enzimas e proteínas para a referida cultura.

\section{MATERIAL E MÉTODOS}

Foram utilizadas dez cultivares de soja, sendo elas MG/ 
BR 46 (Conquista), BR/IAC 21, BRSMG Liderança, BRSMG Confiança, Splendor, UFV 16 (Capinópolis), BRSMG Garantia, FT 2000, Monarca e BRSMG 68 (Vencedora).
As cultivares Liderança, Confiança, Garantia e Monarca são cultivares protegidas pelo SNPC. A genealogia de cada cultivar está apresentada na Tabela 1.

TABELA 1. Genealogia das dez cultivares de soja analisadas.

\begin{tabular}{|c|c|c|}
\hline NÚMERO & NOME & GENEALOGIA \\
\hline 1 & MG/BR 46 (Conquista) & Lo76-4484 / Numbaíra ${ }^{1}$ \\
\hline 2 & $\mathrm{BR} / \mathrm{IAC} 21$ & RC IAC 8 / (IAC $8^{2} /$ FT Cristalina $\left.{ }^{3}\right)$ \\
\hline 3 & BRSMG Liderança & Centenial / [(Paraná ${ }^{4} /$ Bossier $\left.^{5}\right) /$ Davis $\left.^{6}\right]$ \\
\hline 4 & BRSMG Confiança & Paraná / BR83-147 \\
\hline 5 & Splendor & $\mathrm{IAC} / \mathrm{FT} 2^{7}$ \\
\hline 6 & UFV 16 (Capinópolis) & FT 12 / IAC 8 \\
\hline 7 & BRSMG Garantia & Braxton / (Cariri / FT Cristalina) \\
\hline 8 & FT 2000 & Sem informação \\
\hline 9 & Monarca & Seleção de CAC $1^{8}$ \\
\hline 10 & BRSMG 68 [Vencedora] & Braxton / [FT $5^{9} /\left(\right.$ Dourados $^{10} /$ Ocepar 9-SSI $\left.\left.{ }^{11}\right)\right]$ \\
\hline
\end{tabular}

${ }^{1}$ : progênie F6 selecionada a partir de Davis / IAC 71-113; ${ }^{2}$ : Bragg / (Hill / PI240664); Bragg: Jackson / D49-2491 (D49-2491: irmã de Lee); ${ }^{3}$ : cruzamento

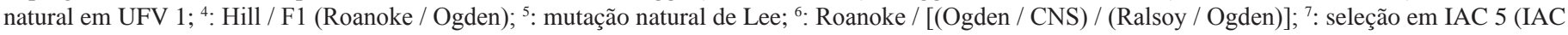
5: Hill / Hood); ${ }^{8}$ : seleção em IAC 8; ${ }^{9}$ : FT 9510 / Sant’Ana; ${ }^{10}$ : seleção em Andews; ${ }^{11}$ : mutação natural em Paraná.

As avaliações dos descritores morfológicos foram realizadas em dois períodos similares de cultivo, como recomendado pela LPC (Brasil, 1997). O experimento foi conduzido em casa de vegetação, no verão, em delineamento inteiramente casualizado, com nove repetições para cada cultivar. Os seguintes descritores morfológicos, recomenda-dos pelo SNPC, foram avaliados: Plântula - (avaliação realizada durante a fase de emergência a cotilédones abertos, correspondendo ao estádio de desenvolvimento vegetativo VC): pigmentação de antocianina no hipocótilo; Planta (avaliações realizadas no início de formação das vagens e quandoessasjáestavammaduras, correspondendoaos estádios reprodutivos R3 e R8, respectivamente) tipo de crescimento (determinado, semi-determinado ou indeterminado), altura da planta (baixa, média ou alta), cor da pubescência na haste principal (cinza, marrom clara ou marrom média), densidade da pubescência na haste principal ( baixa, média ou alta); Folha - (avaliações realizadas durante a floração plena, correspondendo ao estádio reprodutivo R2) intensidade da cor verde (clara, média ou escura), forma do folíolo lateral (lanceolada estreita, lanceolada, triangular, oval-pontiaguda ou oval-arredondada), rugosidade (ausente ou muito fraca, fraca, média, forte ou muito forte); Flor - (avaliação realizada durante a floração plena, correspondendo ao estádio reprodutivo R2) cor (branca ou roxa) Vagem - (avaliação realizada com 95\% das vagens maduras, correspondendo ao estádio reprodutivo R8) cor (cinza clara, cinza escura, marrom clara, marrom média ou marrom escura); Semente - (avaliações realizadas após a colheita) tamanho (pequeno, médio ou grande), forma (esférica, esférico-achatado, alongada ou alongada-achatada), peso de 100 sementes (baixo, médio ou alto), intensidade do brilho do tegumento (baixa, média ou alta), cor do tegumento, excluindo o hilo (amarela, amarelo-esverdeada, verde, marrom clara, marrom média, marrom escura ou preta), cor do hilo (cinza, amarela, marrom clara, marrom, preta imperfeita ou preta), reação à peroxidase (positiva ou negativa), sendo o teste de peroxidase realizado segundo as prescrições das Regras para Análise de Sementes (Brasil, 1992); Ciclo vegetativo - (avaliado da emergência à floração): precoce, médio ou tardio; Ciclo total - (avaliado da emergência à maturação) precoce, semi-precoce, médio, semi-tardio ou tardio. Além destes descritores, aqueles recomendados pela UPOV (UPOV, 1998) também foram avaliados como: Plântula - (avaliação realizada durante a fase de emergência a cotilédones abertos, correspondendo ao estádio de desenvolvimento vegetativo VC) intensidade da coloração com antocianina no hipocótilo (muito fraca, fraca, média, forte ou muito forte); Planta (avaliação realizada quando a planta apresentar 60\% das flores abertas, correspondendo aos estádios reprodutivos R1 e R2) hábito de crescimento (ereto, ereto para semiereto, semi-ereto, semi-ereto para horizontal ou horizontal); 
Semente - (avaliação realizada após a colheita): cor do funículo (igual ou diferente da cor do tegumento).

No momento da debulha das vagens, verificou-se que as mesmas apresentavam diferenças de cultivar para cultivar em relação à quantidade, cor da pubescência, posição e tamanho do dente apical. Tais características foram incluídas na lista de descritores morfológicos avaliados.

A análise dos descritores morfológicos consistiu na observação visual de cada característica e da posterior comparação dos genótipos.

Para a análise eletroforética de proteínas de armazenamento, foram utilizados dois tampões de extração, sendo eles $\mathrm{NaCl}$ 0,5M e tampão borato 0,02M pH 9,0 juntamente com tampão desnaturante $(0,02 \mathrm{M}$ de Tris $\mathrm{HCl}$ pH 8,$6 ; 1 \%$ de SDS; $0,3 \%$ de $\beta$-mercaptoetanol; $8,3 \%$ de glicerol). Foram utilizados $1000 \mu \mathrm{L}$ de tampão de extração em 100mg de 50 sementes moídas, de acordo com as recomendações de Konarev (1988).

As amostras extraídas com $\mathrm{NaCl}$ 0,5M foram agitadas por 30 minutos e centrifugadas a 16.000xg por três minutos, sendo coletado o sobrenadante. As amostras extraídas com tampão borato foram agitadas por 10 minutos e centrifugadas a $16.000 x g$ por três minutos. Foram adicionados $750 \mu \mathrm{L}$ de tampão desnaturante ao sobrenadante, sendo as amostras aquecidas a $90^{\circ} \mathrm{C}$ por dois minutos. O preparo das amostras extraídas pelos dois métodos de extração consistiu na adição de $40 \mu \mathrm{L}$ de tampão da amostra em $10 \mu \mathrm{L}$ de extrato protéico. Os tampões da amostra utilizados foram $5 \mathrm{~mL}$ de glicerol; 0,6M de Tris-HCl pH 6,8 e 2,5mg de azul de bromofenol, para os extratos obtidos tampão $\mathrm{NaCl} 0,5 \mathrm{M}$, e $5 \mathrm{~mL}$ de glicerol; 0,5M de Tris-HCl 0,4\% de SDS $\mathrm{pH} 8,0 ; 0,5 \mathrm{~mL}$ de $\beta$-mercaptoetanol e $2,5 \mathrm{mg}$ de azul de bromofenol para os extratos extraídos com tampão borato e tampão desnaturante. Foram aplicados $40 \mu \mathrm{L}$ de cada amostra e $10 \mu \mathrm{L}$ de padrão de peso molecular de proteínas, variando de 10 a $200 \mathrm{Kda}$ em gel de poliacrilamida 12,5\% (gel separador) e 6\% (gel concentrador). A eletroforese e a revelação dos géis foram realizadas de acordo com o recomendado por Alfenas (1998).

Para a extração de proteínas resistentes ao calor, seguiuse o protocolo utilizado por Roveri José et al. (2004), com algumas modificações. Sementes secas das cultivares foram embebidas em água por um período de uma hora para facilitar a retirada dos eixos embrionários. Foram utilizados 11 eixos de cada cultivar, os quais foram macerados com tampão de extração constituído de $50 \mathrm{mM}$ de Tris $\mathrm{HCl} \mathrm{pH} \mathrm{7,5;} \mathrm{500mM} \mathrm{de}$ $\mathrm{NaCl} ; 5 \mathrm{mM}$ de $\mathrm{MgCl}_{2}$ e $1 \mathrm{mM}$ de PMSF. O volume de tampão de extração utilizado foi de 10 vezes o peso médio de cada amostra. As amostras foram centrifugadas a $16.000 \mathrm{xg}$, por 30 minutos, a $4^{\circ} \mathrm{C}$ e o sobrenadante incubado em banho-maria a $85^{\circ} \mathrm{C}$ por 15 minutos. Foi realizada uma nova centrifugação nas mesmas condições acima citadas e o sobrenadante coletado. Foram adicionados $40 \mu \mathrm{L}$ de tampão da amostra constituído de Tris-HCl 0,5M pH 7,5; 12,5\% de glicerol; 2,3\% de SDS e $0,1 \%$ de azul de bromofenol em $10 \mu \mathrm{L}$ de extrato protéico. O preparo das amostras para aplicação no gel, eletroforese e revelação dos géis foi realizado como descrito anteriormente para a análise de proteínas de armazenamento.

A avaliação dos géis de proteínas de armazenamento e resistentes ao calor constou da observação da presença e ausência de bandas em cada genótipo.

Para a extração das enzimas, seguiu-se o protocolo utilizado por Aguero (2002). Foi utilizado 100mg de sementes secas de cada cultivar, moídas em moinho refrigerado e obtidas de uma única amostra de mais de 50 sementes por cultivar, de acordo com as recomendações de Konarev (1988). Foram adicionados $700 \mu \mathrm{L}$ de tampão de extração, o qual consistiu de dois tampões: uma parte de tampão $0,2 \mathrm{M}$ de borato de lítio $(0,2 \mathrm{M}$ de hidróxido de lítio $\mathrm{pH} 8,3$ titulado com $0,4 \mathrm{M}$ de ácido bórico) e nove partes de tampão $0,2 \mathrm{M}$ de Tris citrato $\mathrm{pH} 6,5(0,2 \mathrm{M}$ de Tris-base $\mathrm{pH}$ 6,5 titulado com $0,4 \mathrm{M}$ de ácido cítrico) e $0,15 \%$ de $\beta$-mercaptoetanol. As amostras com tampão de extração foram deixadas na geladeira por uma noite e centrifugadas a $16.000 x g$ por 30 minutos a $4^{\circ} \mathrm{C}$. Foram aplicados $60 \mu \mathrm{L}$ do sobrenadante em gel de poliacrilamida 7,5\% (gel separador) e 4,5\% (gel concentrador). A eletroforese e a revelação dos géis para os sistemas enzimáticos manose 6-fosfato isomerase (MPI), $\alpha$ e $\beta$-amilase, superóxido dismutase (SOD), álcool desidrogenase (ADH), esterase (EST), lipoxigenase (LOX), urease(EU), 6-fofogluconato desidrogenase (PGD), isocitrato desidrogenase (IDH), peroxidase (PO), fosfoglucomutase (PGM), fosfatase ácida (ACP) e diaforase (DIA), foram realizadas de acordo com Alfenas (1998). Os sete últimos sistemas enzimáticos são recomendados pela UPOV (UPOV, 1998) para a caracterização de cultivares de soja.

A similaridade genética entre cada par de genótipos foi calculada utilizando os dados obtidos na avaliação dos descritores morfológicos e sistemas isoenzimáticos. Para os descritores morfológicos considerou-se os 26 descritores avaliados equivalente a $100 \%$ de similaridade e o número de descritores em comum entre cada par de genótipos sendo o valor de similaridade genética a ser encontrado. Para os dados isoenzimáticos a similaridade genética foi calculada pelo coeficiente de Jaccard. Os genótipos foram agrupados pelo método UPGMA (Unweighted Pair Method), utilizando-se 
o programa NTSYS versão 2.11 (Rohlf, 1992). A correlação de Pearson foi calculada para verificação do ajuste entre cada matriz de similaridade genética e os respectivos dendrogramas, utilizando-se o programa GENES (Cruz, 2001).

\section{RESULTADOS E DISCUSSÃO}

Os 26 descritores morfológicos avaliados nos estádios de plântula, planta adulta e semente possibilitaram a distinção de todas as cultivares. Pelo dendrograma obtido com base nestes descritores, as cultivares foram separadas em quatro grupos: 1) Conquista, UFV 16, BR/IAC 21 e Liderança; 2) Splendor e Vencedora; 3) FT 2000 e Monarca; 4) Confiança e Garantia (Figura 1A). A maior similaridade entre as cultivares do grupo $1(>0,62)$ pode ser explicada pela presença de ancestrais em comum na genealogia destas cultivares, como as cultivares D49-2491, Lee e Davis. De forma semelhante, a cultivar Hill está presente na genealogia das cultivares Splendor e Vencedora, como também de Confiança e Garantia, apesar destas apresentarem uma menor similaridade genética entre re si. Para as cultivares FT 2000 e Monarca; estas devem possuir ancestrais em comum, apesar da genealogia de FT 2000 não ser conhecida.

A correlação de Pearson obtida entre a matriz de similaridade genética e o dendrograma, com base nos descritores morfológicos, foi $r=0,82$, indicando que os agrupamentos obtidos estão de acordo com os valores de similaridade genética entre cada par de genótipos.

Alguns descritores morfológicos foram específicos para determinadas cultivares, como intensidade de antocianina muito forte no hipocótilo das plântulas da cultivar Conquista; folíolos laterais oval-pontiagudos e ciclo total semi-precoce para a cultivar Liderança; rugosidade muito forte e sementes de tamanho pequeno para a cultivar Confiança; vagens de coloração marrom claro para a cultivar Splendor; plantas de altura baixa e dente apical grande para a cultivar UFV 16; intensidade clara da cor verde das folhas, folíolos laterais lanceolado-estreitos e ciclo vegetativo tardio para a cultivar Garantia, e brilho do tegumento de intensidade média para a cultivar Vencedora.

Os descritores morfológicos avaliados na fase de plântula e os avaliados nas sementes devem ser preferidos, pois possibilitam a obtenção rápida de resultado, não sendo necessário aguardar por plantas adultas. As cultivares Conquista, Confiança e Vencedora apresentaram descritores morfológicos em sementes e plântulas que foram úteis para sua separação das demais cultivares, como mencionado acima.
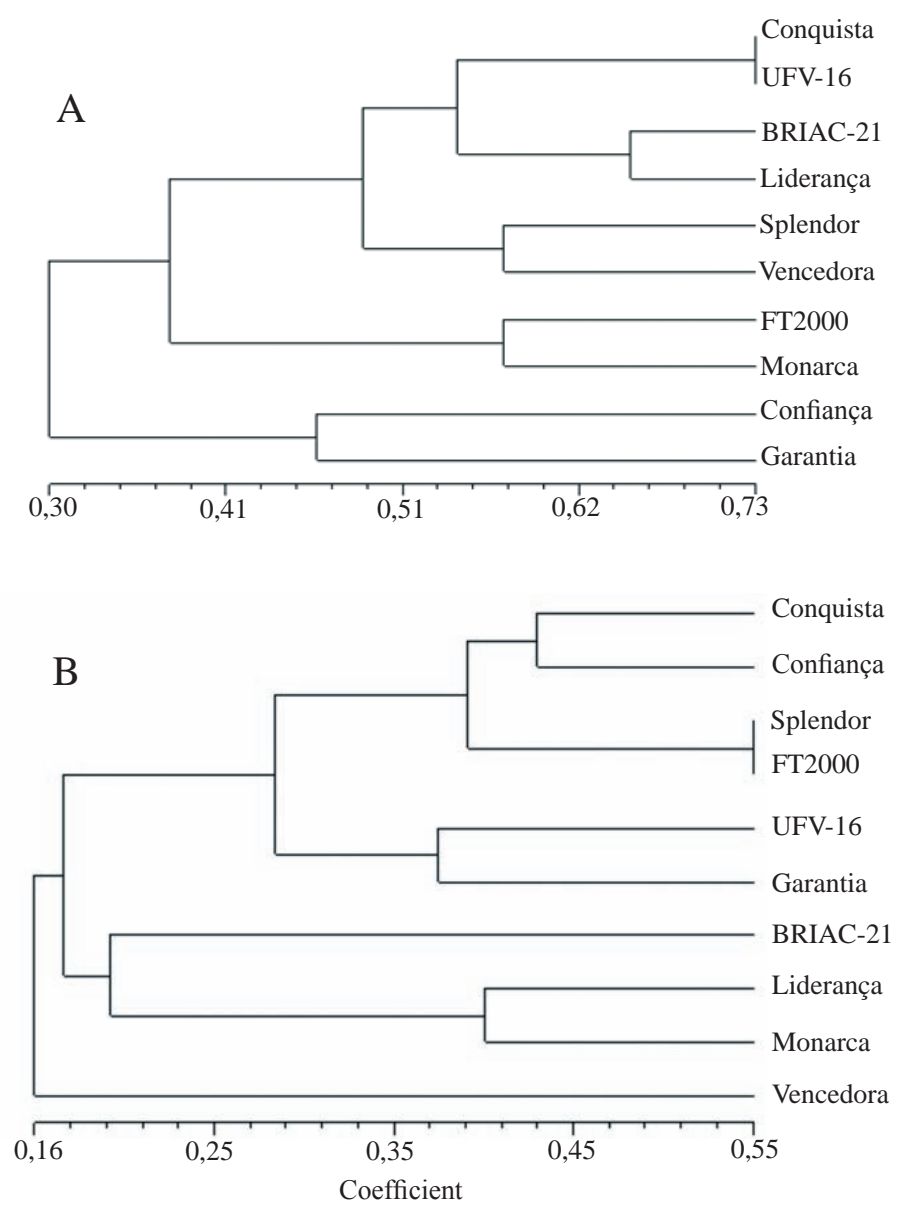

FIGURA 1. Dendrogramas de dez cultivares de soja, obtidos pela análise de agrupamento UPGMA, com base nos dados de descritores morfológicos (A) e marcadores isoenzimáticos (B).

As cultivares Liderança, Confiança, Garantia e Monarca são cultivares protegidas, possuindo descritores definidos no catálogo de cultivares de soja protegidas, do SNPC (Brasil, 2002). A maioria dos descritores morfológicos observados no presente trabalho, para essas cultivares, está de acordo com os descritores publicados. Entretanto, alguns descritores não foram coincidentes, como altura de planta, forma da semente, brilho do tegumento e cor do hilo, o que mostra que os descritores morfológicos são passíveis de variações.

Dentre os marcadores morfológicos sugeridos para serem avaliados nas vagens, o tamanho do dente apical foi útil na caracterização das cultivares avaliadas. A cultivar 
UFV 16, como mencionado anteriormente, apresentou dente apical grande, sendo este um descritor específico para esta cultivar. Sendo assim, sugerimos o tamanho do dente apical das vagens de soja como um novo descritor morfológico para a cultura. Nogueira et al. (2007) e Boldt et al. (2007) também sugeriram novos descritores morfológicos, baseados na avaliação de plântulas, para a cultura da soja, uma vez que, os trinta e oito descritores recomendados pelo SNPC não têm sido suficientes.

Os descritores morfológicos avaliados possibilitaram a caracterização e distinção da maioria das cultivares utilizadas, sendo úteis para os testes DHE (distinguibilidade, homogeneidade e estabilidade). Vale ressaltar que, para o emprego de descritores morfológicos em testes de caracterização de cultivares, deve-se considerar o estado nutricional das plantas, o que garantirá a manifestação das características a serem avaliadas, minimizando o efeito ambiental.

Em relação aos marcadores bioquímicos de proteínas, os métodos de extração de proteínas de armazenamento e de proteínas resistentes ao calor foram eficientes. As dez cultivares avaliadas não apresentaram diferenças entre si quando se utilizou o tampão $\mathrm{NaCl}$ 0,5M para a extração das proteínas de armazenamento. Quando se utilizou o tampão borato $0,02 \mathrm{M}+$ tampão desnaturante, três bandas polimórficas foram observadas, sendo uma de peso molecular de $20 \mathrm{Kda}$ presente nas cultivares Conquista, BR/IAC 21, Garantia e Monarca, uma segunda de peso molecular de $30 \mathrm{KDa}$ presente nas cultivares Conquista, BR/IAC 21 e Garantia, e uma terceira de peso molecular entre 50 e $60 \mathrm{KDa}$ presente nas cultivares Conquista, BR/IAC 21, Liderança, Confiança, Garantia e Monarca. Três padrões eletroforéticos diferentes foram obtidos, sendo as cultivares separadas em três grupos: 1) contendo as cultivares Conquista, BR/IAC 21 e Garantia; 2) contendo as cultivares Liderança, Confiança e Monarca; 3) contendo as cultivares Splendor, UFV 16, FT 2000 e Vencedora.

Em relação às proteínas resistentes ao calor, o polimorfismo encontrado foi menor do que o esperado, uma vez que essas se mostraram altamente polimórficas na caracterização de cultivares de algodão e milho (Mann, 2002; Roveri José et al., 2004). Foi observada apenas uma banda polimórfica correspondente a $30 \mathrm{Kda}$, a qual está presente somente nas cultivares Conquista, Confiança, Splendor, FT 2000 e Monarca. O baixo polimorfismo detectado pelos marcadores bioquímicos de proteínas está de acordo com o observado por Aguero (2002). Segundo este autor, a ocorrência de um padrão geral de proteínas entre diferentes cultivares de soja pode ser atribuída à composição semelhante de proteínas presentes na semente. Menezes et al. (2008), relataram uma baixa eficiência no uso de proteínas resistentes ao calor na caracterização de cultivares de soja.

O protocolo utilizado para a extração de isoenzimas foi eficiente para a detecção de atividade de 11 dos 14 sistemas enzimáticos avaliados. Foram observadas variações nos padrões eletroforéticos dos sistemas enzimáticos superóxido dismutase (SOD), diaforase (DIA), fosfoglucomutase (PGM), esterase (EST), álcool desidrogenase $(\mathrm{ADH})$, isocitrato desidrogenase (IDH) e peroxidade (PO). Os demais sistemas enzimáticos se apresentaram monomórficos, não sendo úteis para a caracterização das cultivares estudadas.

Oito, das dez cultivares de soja, puderam ser distinguidas por meio dos marcadores isoenzimáticos, sendo que para cada uma dessas cultivares foi obtido pelo menos um padrão eletroforético específico (Figuras 2 e 3). A cultivar BR/IAC 21, por exemplo, pode ser distinguida das demais pelos sistemas enzimáticos superóxido dismutase, diaforase e esterase; a cultivar Liderança pela enzima esterase; Confiança pela fosfoglucomutase, esterase e peroxidase; UFV 16 pela isocitrato desidrogenase; Garantia pela álcool desidrogenase e isocitrato desidrogenase; FT 2000 por álcool desidrogenase; Monarca por superóxido dismutase e Vencedora pela superóxido dismutase, álcool desidrogenase e isocitrato desidrogenase (Figuras 2 e 3). Somente as cultivares Conquista e Splendor não apresentaram padrões eletroforéticos específicos.

Pelo dendrograma obtido a partir dos coeficientes de similaridade de Jaccard e apresentado na Figura 1B, as dez cultivares de soja foram agrupadas em seis grupos: 1) contendo as cultivares Conquista e Confiança; 2) contendo Splendor e FT 2000; 3) contendo UFV 16 e Garantia; 4) contendo somente a cultivar BR/IAC 21; 5) contendo as cultivares Liderança e Monarca; e 6) contendo a cultivar Vencedora. As cultivares Confiança e Conquista, possuem as cultivares Roanoke e Ogden em suas genealogias, assim como a cultivar D49-2491 está presente nas genealogias das cultivares UFV 16 e Garantia, e Hill nas genealogias de Liderança e Monarca. No entanto, a correlação de Pearson entre a matriz de similaridade genética obtida a partir dos dados isoenzimáticos e o dendrograma foi $\mathrm{r}=0,41$, o que indicou que os agrupamentos não refletem os reais valores de similaridade genética calculados, mesmo a maioria dos agrupamentos podendo ser explicada pela genealogia. A baixa correlação pode estar relacionada à utilização de um número insuficiente de locos isoenzimáticos, uma vez que, para estudos de caracterização de cultivares são recomendados 
20 locos isoenzimáticos polimórficos e neste trabalho foram

utilizados sete locos polimórficos (Konarev, 1988).
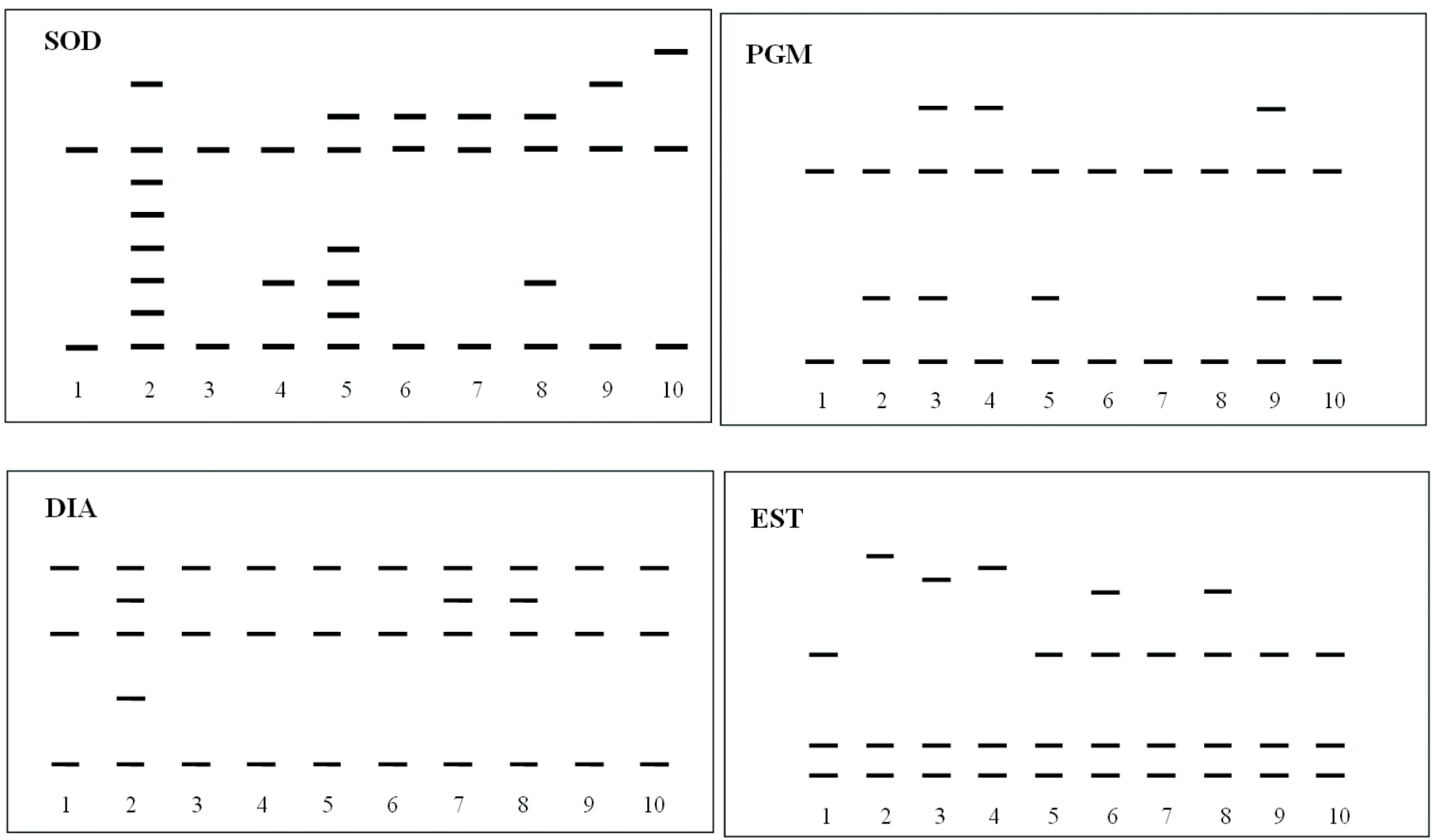

FIGURA 2. Zimogramas dos sistemas isoenzimáticos superóxido dismutase (SOD), diaforase (DIA), fosfoglucomutase (PGM) e esterase (EST), de sementes secas de soja das cultivares Conquista (1), BR/IAC 21 (2), Liderança (3), Confiança (4), Splendor (5), UFV 16 (6), Garantia (7), FT 2000 (8), Monarca (9) e Vencedora (10).

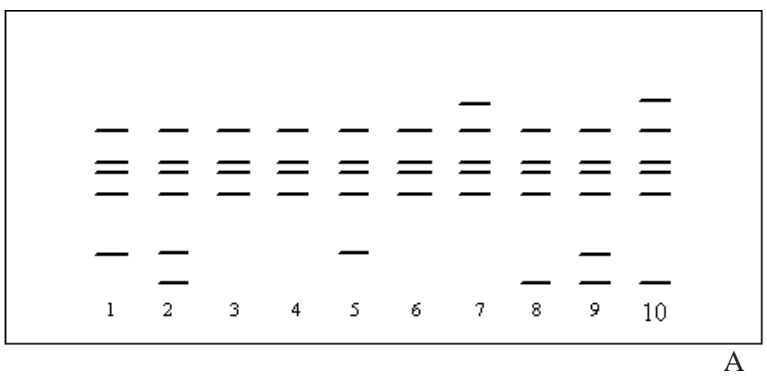

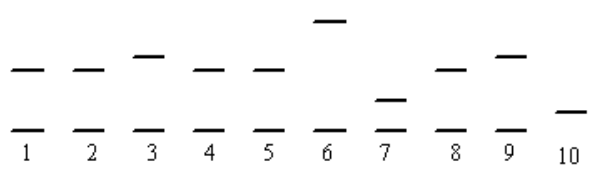

$\mathrm{B}$

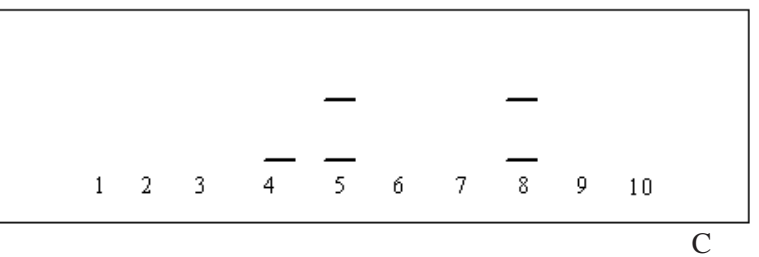

FIGURA 3. Zimogramas das enzimas álcool desidrogenase (ADH), isocitrato desidrogenase (IDH) e peroxidase (PO) de sementes secas de soja das cultivares Conquista (1), BR/IAC 21 (2), Liderança (3), Confiança (4), Splendor (5), UFV 16 (6), Garantia (7), FT 2000 (8), Monarca (9) e Vencedora (10). 
Pelos resultados obtidos no presente trabalho, marcadores bioquímicos de proteínas e isoenzimas são úteis na caracterização de cultivares de soja, havendo protocolos de fácil aplicação para extração de proteínas e isoenzimas. Sendo assim, recomenda-se a utilização de tais marcadores, juntamente com os descritores morfológicos, em estudos de caracterização de cultivares de soja.

\section{CONCLUSÕES}

Marcadores bioquímicos de proteínas de armazenamento e de isoenzimas, bem como marcadores moleculares são eficientes na caracterização de cultivares de soja.

Proteínas resistentes ao calor não são úteis para a caracterização de cultivares de soja.

\section{REFERÊNCIAS}

AGRIANUAL 2008: Anuário da agricultura brasileira. São Paulo: Agros Comunicação / FNP Consultoria e Comércio, 2008, 504p.

AGUERO, C.O.P. Padrões eletroforéticos de cultivares de soja (Glycine $\max (\mathrm{L}$.$) Merrill). Pelotas: UFPel. 2002$. 36f. Dissertação (Mestrado em Ciência e Tecnologia de Sementes) - Faculdade de Agronomia Eliseu Maciel, Universidade Federal de Pelotas, Pelotas.

ALFENAS, A.C. Eletroforese de isoenzimas e proteínas afins: fundamentos e aplicações em plantas e microrganismos. Viçosa: UFV, 1998, 574p.

ANTI, A.B. Caracterização de germoplasma de soja e de feijão através de eletroforese de isoenzimas da semente. Bragantia, v. 59, n. 2, p.139-142, 2000.

BOLDT, A.S.; SEDIYAMA, T.; NOGUEIRA, A.P.O.; MATSUO, E.; TEIXEIRA, R.C.; Influência do tamanho de semente na caracterização de descritores adicionais de soja. In: REUNIÃO DE PESQUISA DE SOJA DA REGIÃ̃O CENTRAL DO BRASIL. 29., 2007, Campo Grande. Anais. Londrina: Embrapa Soja, 2007. v.1, p.120-122.

BONOW, S.; AUGUSTIN, E.; FRANCO, D.F.; PETERS, J.A.; TERRES, A.L. Caracterização isoenzimática de genótipos de arroz. Pesquisa Agropecuária Brasileira, v. 36, n. 2, p. 291-300, 2001.

BRASIL. Decreto-lei 9.456 de 28 de abril de 1997. Lei de proteção de cultivares. Diário Oficial da República Federativa do Brasil, Brasília, DF, 28 de abr. 1997. Seção 1. p 79.

BRASIL, Decreto-lei 10.711 de 5 de agosto de 2003. Nova
Lei de Sementes e Mudas. Diário Oficial da República Federativa do Brasil, Brasília, 6 de ag. 2003. Seção 1. p. 1-4.

BRASIL, Ministério da Agricultura e Reforma Agrária. Regras para análise de sementes. Brasília, DF: SNDA/ DNDV/CLAV, 1992. 365p.

BRASIL. Ministério da Agricultura, Pecuária e Abastecimento. Serviço Nacional de Proteção de Cultivares. Catálogo de cultivares protegidas de soja (Glycine max. (L.) Merrill). Brasília, 2002. 133p.

CRUZ, C.D. Programa GENES - versão Windows. Viçosa: Editora UFV, 2001. 64p.

FERREIRA, M.E.; GRATTAPAGLIA, D. Introdução ao uso de marcadores moleculares em análises genéticas. 3 . ed. Brasília, DF: EMBRAPA-CENARGEN, 1998. 220p.

INTERNATIONAL SEED TESTING ASSOCIATION. Species and variety testing. In: INTERNATIONAL rules for seed testing. Bassersdorf: ISTA, 2007. p. 1-32.

KONAREV, V.G. Proteins in cultivar identification. In: INTERNATIONAL SYMPOSIUM, ISTA, 3., 1987, Leningrad, 1988. p. 9-14.

MANN, R.S. Diversidade do complexo colletotrichum e de cultivares de algodoeiro por meio de marcadores moleculares. 2002. 73f. Tese (Doutorado em Fitotecnia) Universidade Federal de Lavras, Lavras, 2002.

MENEZES, M.; VON PINHO, E.V. de R.; PEREIRA, A.M.A.R.; OLIVEIRA, J.A. Identificação de cultivares de milho, feijão, algodão e soja por meio de enzimas e proteínas resistentes ao calor. Revista Brasileira de Sementes, v.30, n.2, p.111-122, 2008.

NOGUEIRA. A.P.O.; SEDIYAMA, T.; CRUZ, C.D.; REIS, M.S.; PEREIRA, D.G.; MATSUO, E. Análise discriminante na caracterização de novos descritores em soja [Glycine $\max ($ L.) Merrill]. In: REUNIÃO DE PESQUISA DE SOJA DA REGIÃO CENTRAL DO BRASIL. 29., 2007, Campo Grande. Anais... Londrina: Embrapa Soja, 2007. p.117119

ROHLF, F.J. Numerical taxonomy and multivariate analysis system. New York, 1992, 470p. Version 2.11

ROVERI JOSÉ, S.C.B.; VON PINHO, E.V.R.; SALGADO, K.C.; VON PINHO, R.G. Identificação de cultivares de milho por meio de proteínas resistentes ao calor. Revista Brasileira de Milho e Sorgo, v. 3, n. 1, p.1-9, 2004.

SALGADO, K.C. de C. Certificação da pureza genética em sementes híbridas de milho por meio de marcadores morfológicos e moleculares. 2001, 67f. Dissertação 
(Mestrado em Fitotecnia) - Universidade Federal de Lavras, Lavras, 2001.

SNPC -Serviço Nacional de Proteção de Cultivares. MAPA - Ministério da Agricultura, Pecuária e Abastecimento. 2008. Disponível em : $<$ http://www.agricultura.gov.br $>>$ Acesso em: 18 mar. 2008.

INTERNATIONAL UNION FOR THE PROTECTION OF NEW VARIETIES OF PLANTS. Directrices para la ejecución del examen de la distinción, la homegeneidad y la estabilidad (Glycine max (L.) Merrill). Genebra, 1998, 12p.

VIEIRA, E.S.N. Similaridade genética entre cultivares de feijão do grupo carioca por meio de marcadores morfológicos e moleculares visando a certificação da pureza genética. 2000. 84f. Dissertação (Mestrado em Fitotecnia) - Universidade Federal de Lavras, Lavras, 2000. 